\title{
MEDIA PEMBELAJARAN TENSES UNTUK ANAK SEKOLAH MENENGAH PERTAMA BERBASIS ANDROID MENGGUNAKAN CONSTRUCT 2
}

\author{
Andre Chandra Laudhana ${ }^{1}$, Ajeng Savitri Puspaningrum ${ }^{2}$ \\ Universitas Teknokrat Indonesia ${ }^{1,2}$
}

andrechandra469@gmail.com¹, ajeng.savitri@teknokrat.ac.id ${ }^{2}$

Abstract

As an International language, English is widely used in various fields which cause we have to learn English. In a conducted researh, it is stated that learning language is best done at early childhood. In learning English, one of the most difficult thing to do is learning the Tenses. Recent studies has establish some learning media have been developed in order to facilitate someone to learn English, such as. But, it is done as learning media for grown up and the UI is not attractive for children. That's why it's need to develop an application that will attract children to learn Tenses. This study examines how construct 2 can be implemented to develop an android based application as tenses learning media. The application is developed using Multimedia Development Life Cycle and Construct 2 and tested using Alpha and Beta Testing Method. The alpha testing showed that the application is able to run as the requirement specification given. The beta testing showed that 97,8\% respondend agreed that the application can facilitated and attract them to learn English Tenses. It is found that the application ease and attract children to learn English tenses.
\end{abstract}

Keywords: Android, Construct 2, Learning, Media, Tenses.

\begin{abstract}
Abstrak
Sebagai bahasa Internasional, bahasa Inggris banyak digunakan di berbagai bidang yang menyebabkan kita harus belajar bahasa Inggris. Dalam penelitian yang dilakukan, dinyatakan bahwa belajar bahasa paling baik dilakukan pada anak usia dini. Dalam belajar bahasa Inggris, salah satu hal yang paling sulit dilakukan adalah mempelajari Tenses. Studi terbaru telah menetapkan beberapa media pembelajaran telah dikembangkan untuk memfasilitasi seseorang untuk belajar bahasa Inggris, seperti. Tapi, itu dilakukan sebagai media pembelajaran untuk orang dewasa dan UI tidak menarik bagi anak-anak. Itu sebabnya perlu mengembangkan aplikasi yang akan menarik anak-anak untuk belajar Tenses. Penelitian ini mengkaji bagaimana konstruk 2 dapat diimplementasikan untuk mengembangkan aplikasi berbasis android sebagai media pembelajaran tegang. Aplikasi ini dikembangkan menggunakan Multimedia Development Life Cycle dan Construct 2 dan diuji menggunakan Metode Pengujian Alpha dan Beta. Pengujian alpha menunjukkan bahwa aplikasi tersebut dapat berjalan sesuai spesifikasi kebutuhan yang diberikan. Pengujian beta menunjukkan bahwa $97,8 \%$ responden setuju bahwa aplikasi dapat memfasilitasi dan menarik mereka untuk belajar Bahasa Inggris Tenses. Ditemukan bahwa aplikasi ini memudahkan dan menarik anak-anak untuk belajar bahasa Inggris.
\end{abstract}

Kata Kunci: Android, Cosntruct 2, Media, Pembelajaran, Tenses. 
To cite this article:

Andre Chandra Laudhana, Ajeng Savitri Puspaningrum (2020). MEDIA PEMBELAJARAN TENSES UNTUK ANAK SEKOLAH

MENENGAH PERTAMA BERBASIS ANDROID MENGGUNAKAN CONSTRUCT 2. Jurnal Informatika dan Rekayasa Perangkat Lunak Vol. (1), 25-35

\section{PENDAHULUAN}

Bahasa Inggris merupakan bahasa internasional yang kerap digunakan di berbagai bidang. Bahasa Inggris sudah dimasukan kedalam kurikulum pendidikan nasional. Banyak lembaga sekolah mengenalkan Bahasa Inggris kepada anak didik sebagai bahasa keseharian di dalam lingkungan sekolah. Dalam Bahasa Inggris grammar atau tata bahasa merupakan bagian yang tak terpisahkan, salah satu materi pokok yang dipelajari di dalam grammar adalah tenses (Shobirin, 2008).

Tenses merupakan salah satu dasar dalam mempelajari Bahasa Inggris. Tenses digunakan untuk menyampaikan suatu maksud, tujuan, keinginan, pernyataan, berita, peristiwa, tindakan atau lainnya secara lisan maupun secara tertulis agar dapat dimengerti atau dipahami dengan jelas dan benar (Susanto dan Mahfan, 2005). Dalam mempelajari tenses terkadang siswa kesulitan karena banyaknya materi yang harus dipelajari (Adrian, 2019), setiap tenses memiliki rumus yang berbeda oleh sebab itu anak atau siswa harus menghafalkanya, salah satu cara yang paling efektif adalah dengan sesering mungkin berlatih dengan melihat contoh-contoh kalimat dan mengerjakan soal-soal dari tenses.

Untuk mempermudah dalam penyampaian tenses pada anak sekolah menengah pertama (SMP), maka dibuatlah sebuah media pembelajaran tenses. Media pembelajaran adalah alat bantu pada proses belajar baik di dalam maupun diluar kelas, lebih lanjut dijelaskan bahwa media pembelajaran adalah komponen sumber belajar atau wahana fisik yang mengandung materi instruksional di lingkungan siswa yang dapat merangsang siswa untuk belajar (Arsyad, 2011). Penelitian ini dilakukan pada SMP PGRI 6 Bandar Lampung. Game HTML dapat di bangun di perangkat Android menggunakan game engine Construct 2.

Construct 2 adalah sebuah tool berbasis Hyper Text Markup Languange (HTML) 5 untuk menciptakan sebuah game. Berbeda dengan tools lain yang mengharuskan pemrogram menuliskan baris demi baris agar tercipta sebuah objek, construct 2 sudah berbasis objek sehingga sangat mudah dalam membuat objek-objek dan mengatur atribut-atribut dari objek tersebut. Construct 2 juga memiliki fitur-fitur yang mudah digunakan dan dimengerti oleh pemrogram pemula (Gullen, 2016).

Berdasarkan latar belakang tersebut, penulis mengusulkan penelitian yang berjudul "Media Pembelajaran Tenses Untuk Anak Sekolah Menengah Pertama Berbasis Android Menggunakan Construct 2". Tujuan utama dari pembuatan aplikasi ini adalah keinginan penulis untuk dapat membantun siswa agar tidak kesulitan dalam mempelajari tenses.

\section{TELAAH PUSTAKA \\ Penelitian terdahulu}

Beberapa penelitian sebelumnya terkait dengan pembelajaran tenses yang penulis rangkum yang dilakukan oleh Wanti Kholiani, et al, Penelitian ini bertujuan untuk mempermudah siswa dalam mempelajari dan memahami tenses Bahasa inggris. Sedangkan penelitian oleh R.Arum, SP, et al, . Penelitian ini bertujuan untuk untuk meningkatkan antusiasme belajara para siswa dalam upaya memahami tenses Bahasa inggris. Sedangkan penelitian yang dilakukan Andre Chandra Laudhana, membahas salah satu pelajaran Bahasa inggris yaitu tenses, dimana tenses memiliki 16 pokok materi yanh harus dipelajari dan dipahami dengan memanfaatkan game engine Construct 2 yang bertujuan untuk dapat membantun siswa agar tidak kesulitan dalam mempelajari tenses.

\section{Media Pembelajaran}

Media pembelajaran adalah alat bantu pada proses belajar baik di dalam maupun diluar kelas (Saputra dkk, 2020), lebih lanjut dijelaskan bahwa media pembelajaran adalah komponen sumber belajar atau wahana fisik yang mengandung materi intruksional di lingkungan siswa yang dapat merangsang siswa untuk belajar (Arsyad, 2011).

\section{Tenses}

Pengertian tenses adalah untuk menyampaikan suatu maksud, tujuan, keinginan, pernyataan, berita, peristiwa, tindakan atau lainnya secara lisan maupun secara tulisan agar dapat dimengerti/dipahami dengan jelas dan benar. Di dalam Bahasa inggris haruslah menggunakan/memakai bentuk waktu yang disebut dengan 
"TENSES" yang tepat dan benar. Adapaun pengertian lain dari tenses adalah suatu gambaran atau penjelasan kapan suatu pernyataan, perbuatan, tindakan, kegiatan, peristiwa, berita itu terjadi/berlangsung, di dalam kalimat, sekarang, masa lampau, atau masa akan dating. Atau perubahan dari kata kerja (verb) yang sesuai dengan waktu terjadinya/berlangsung suatu pristiwa dan keterangan waktunya (tenses) (Susanto dan Mahfan, 2005).

\section{METODE PENELITIAN}

\section{Tahapan penelitian}

Penelitian ini akan dilakukan mengikuti kerangka pemikirian seperti pada gambar 1 berikut.

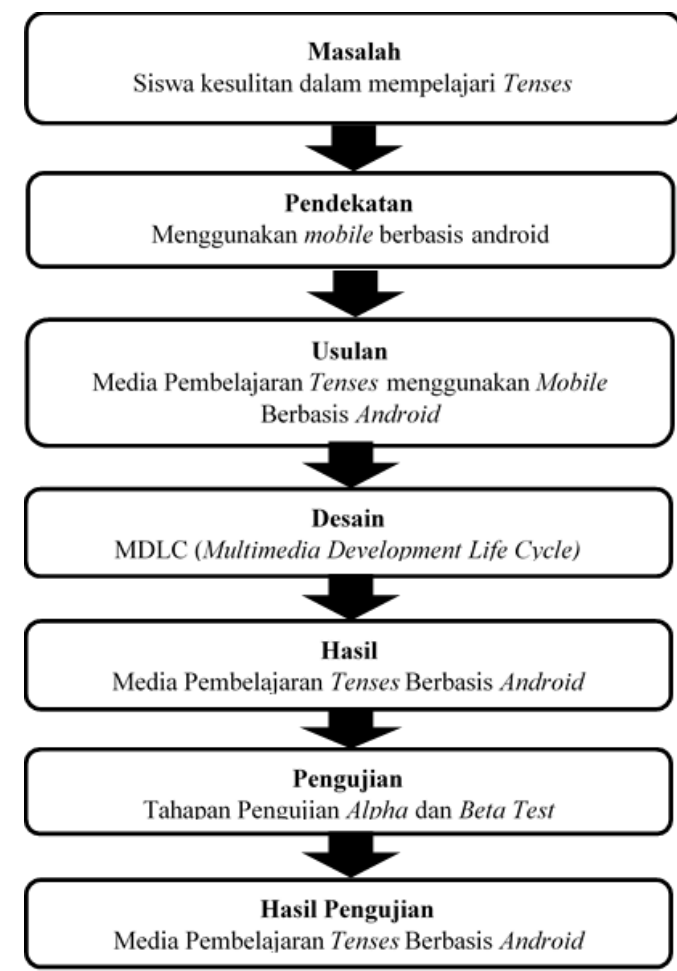

Gambar 1. Kerangka Penelitian

Penelitian ini menggunakan metode pengembangan MDLC (Multimedia Development Life Cycle). Dikutip dari Luther (1994), metodologi pengembangan multimedia terdiri dari enam tahap, yaitu concept (pengonsepan), design (pendesainan), material collecting (pengumpulan materi), assembly (pembuatan), testing (pengujian), dan distribution (pendistribusian). Keenam tahap ini tidak harus berurutan dalam praktiknya, tahap-tahap tersebut dapat saling bertukar posisi. Meskipun begitu, tahap concept memang harus menjadi hal yang pertama kali dikerjakan.

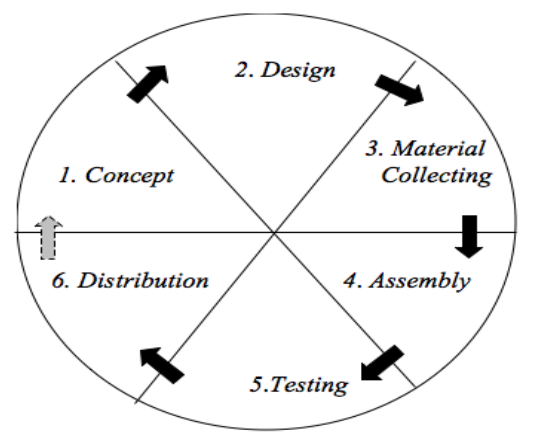

Gambar 1 Multimedia Development Life Cycle 
Berdasarkan siklus tahapan penelitian multimedia, maka tujuan dan literatur dari tahapan multimedia ini dirancang dengan sebuah Work Breakdown Structure (WBS) agar dapat dijelaskan secara rinci dan secara bertahap seperti pada gambar 3 berikut.

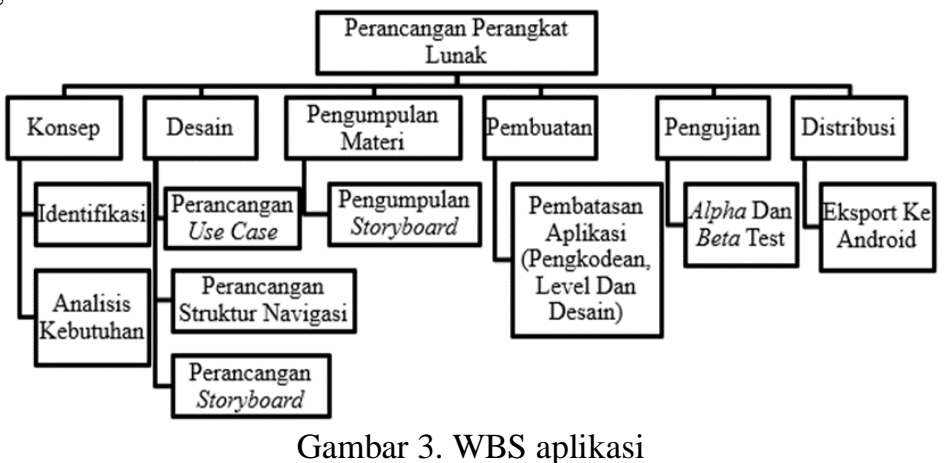

\section{Teknik Pengumpulan Data}

Teknik pengumpulan data yang digukana pada penelitian ini yaitu wawancara dan angket kepada guru dan siswa dari objek penelitian serta dokumentasi.

\section{Pengembangan konsep}

Pada tahap ini ditentukan tujuan dari pembuatan aplikasi, serta audiens atau pengguna. Tujuan dari aplikasi ini adalah merancang aplikasi pembelajaran tenses yang menarik, interaktif, dan edukatif (Rahmanto, 2018). Berikut adalah deskripsi dari konsep aplikasi, Deskripsi konsep dapat dilihat pada tabel 1

Tabel 1. Deskripsi Konsep

\begin{tabular}{|lll|}
\hline Judul & $:$ & $\begin{array}{l}\text { Media pembelajaran Tenses Untuk Anak Sekolah Menengah } \\
\text { Pertama }\end{array}$ \\
\hline Genre & $:$ & Adventure \\
\hline Platform & $:$ & Android \\
\hline Target Audiens & $:$ & Anak SMP (Sekolah Menengah Pertama) \\
\hline$\bullet \quad$ Sentuh & $:$ & Memilih Menu \\
$\bullet \quad$ Belajar & $:$ & Present Tense, Past Tense, Future Tense, Past Future Tense \\
$\bullet \quad$ Bermain & $:$ & Pertanyaan Tenses \\
\hline Audio & $:$ & Vokal dan Instrumen .mp3/.wav \\
\hline Gambar & $:$ & Gambar jpg/png \\
\hline
\end{tabular}

\section{Perancangan}

Untuk menggambarkan perancangan dari tiap scene, perancangan storyboard untuk tahap ini harus dibuat. Gambaran dari scene bentuk visual perancangan, audio, durasi, keterangan, dan narasi untuk suara akan dibuat pada perancangan storyboard. Pada penelitian ini spesifikasi yang akan dibuat berdasarkan adalah Perancangan Use Case, Perancangan Struktur Navigasi dan Perancangan Storyboard. Alur Use Case Diagram dapat dilihat pada gambar 4, struktur navigasi dapat dilihat pada gambar 5 sedangkan rancangan storyboard dapat dilihat pada tabel 2 


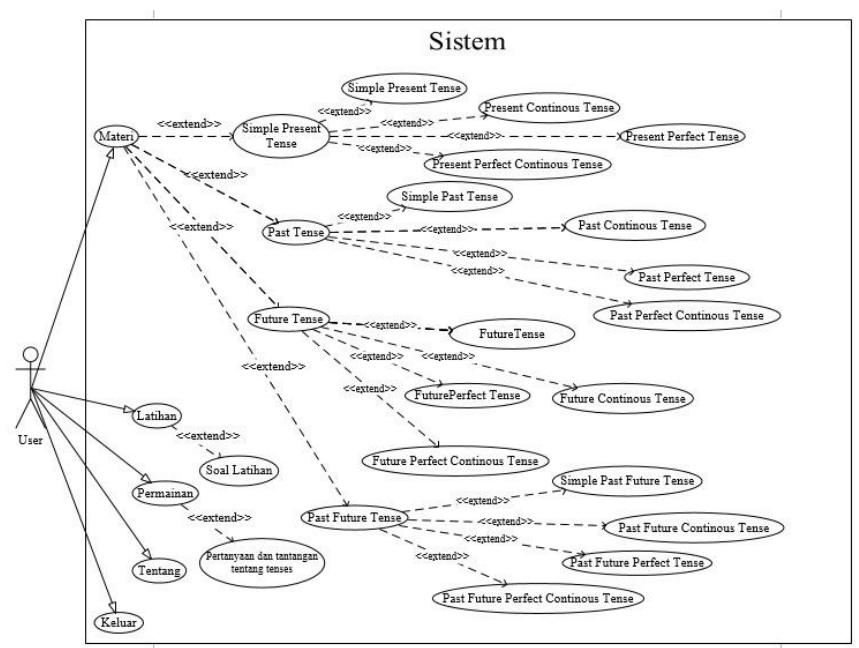

Gambar 4. Use Case Aplikasi

\section{HASIL DAN PEMBAHASAN}

\section{Implementasi}

Tahap implementasi merupakan tahap penerapan dari desain yang telah dirancang ke dalam kode program, implementasi yang dilakukan meliputi implementasi rancangan antarmuka (user interface). Sesuai dengan perancangan antarmuka yang sudah dibuat, maka hasil implementasi rancangan interface adalah sebagai berikut:

\section{Splash Screen Loading}

Pada halaman Splash Screen Loading menampilkan loading bar. Tampilan Splash Screen dapat dilihat pada gambar 1.

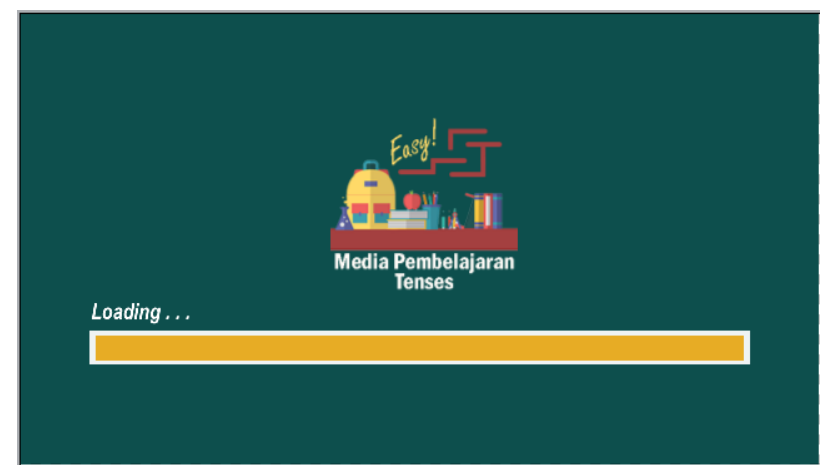

Gambar 1 Tampilan Splash Screen Loading

\section{Menu Mulai Aplikasi}

Pada halaman mulai aplikasi terdapat icon mulai untuk masuk ke menu utama. Tampilan menu mulai aplikasi dapat dilihat pada gambar 2 . 


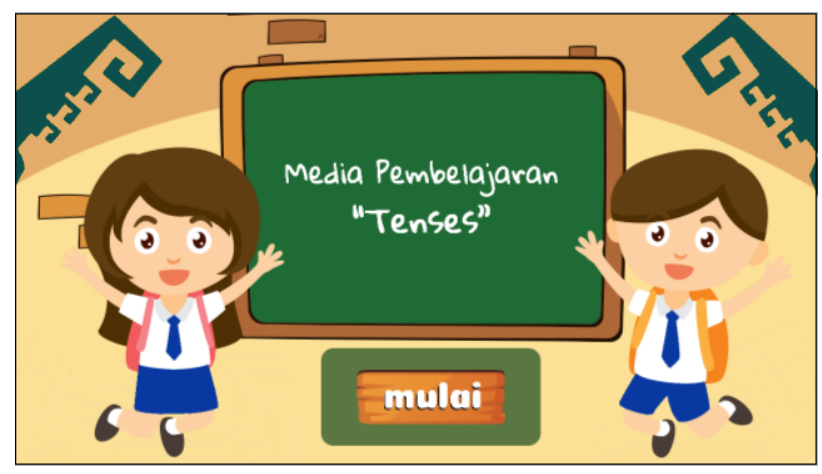

Gambar 2 Menu Mulai Aplikasi

\section{Menu Login Aplikasi}

Pada halaman login aplikasi terdapat textbox untuk mengisi nama user dan juga tombol login. Tampilan login aplikasi dapat dilihat pada gambar 3 .

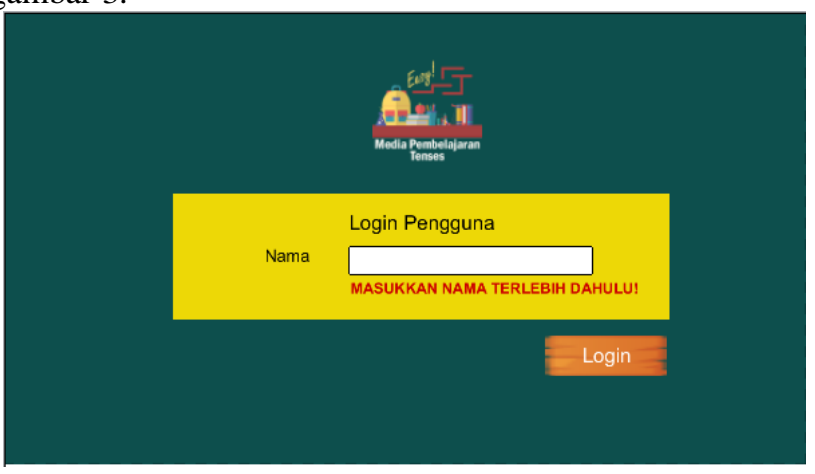

Gambar 3 Menu Login Aplikasi

\section{Menu Utama}

Pada halaman menu utama terdapat icon tombol materi, latihan, permainan, tentang, petunjuk, suara, dan keluar. Tampilan menu utama dapat dilihat pada gambar 4.

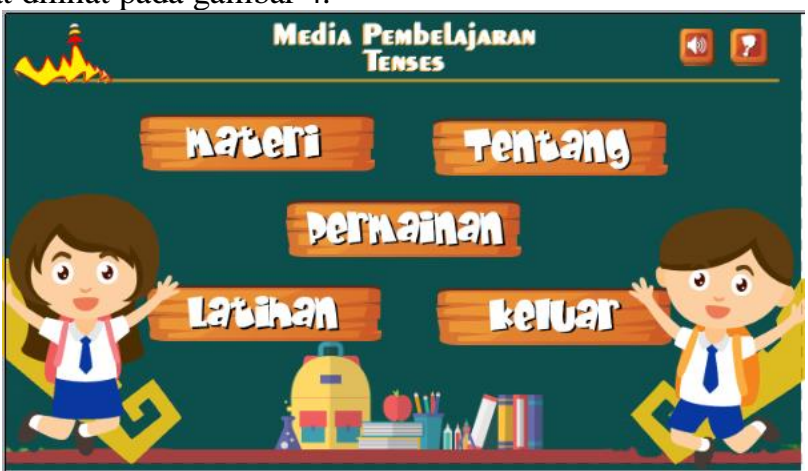

Gambar 4 Menu Utama

\section{Menu Materi}

Halaman menu materi terdiri dari icon tombol materi present tense, past tense, future tense, dan past future tense. Tampilan menu materi dapat dilihat pada gambar 5 . 


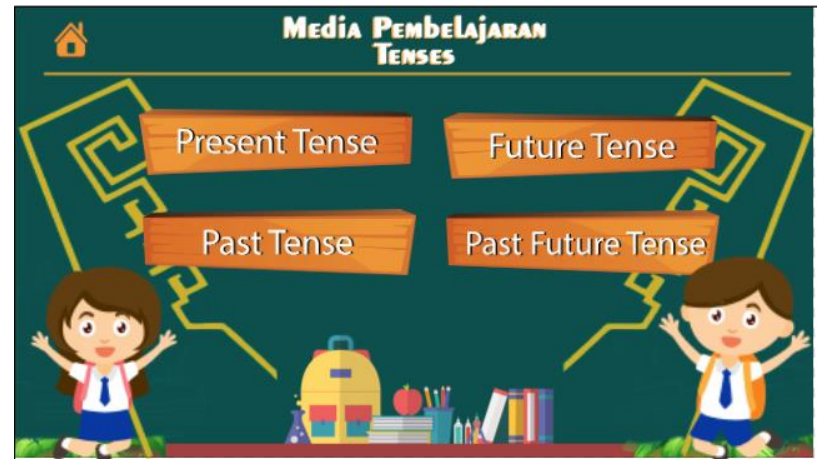

Gambar 5 Menu Materi

\section{Menu Materi Present Tense}

Pada halaman ini terdapat tampilan dari materi present tense, tombol next yang akan menuju materi selanjutanya, icon tombol suara untuk menampilkan suara, dan icon tombol book yang akan menuju ke menu materi. Tampilan menu materi present tense dapat dilihat pada gambar 6.

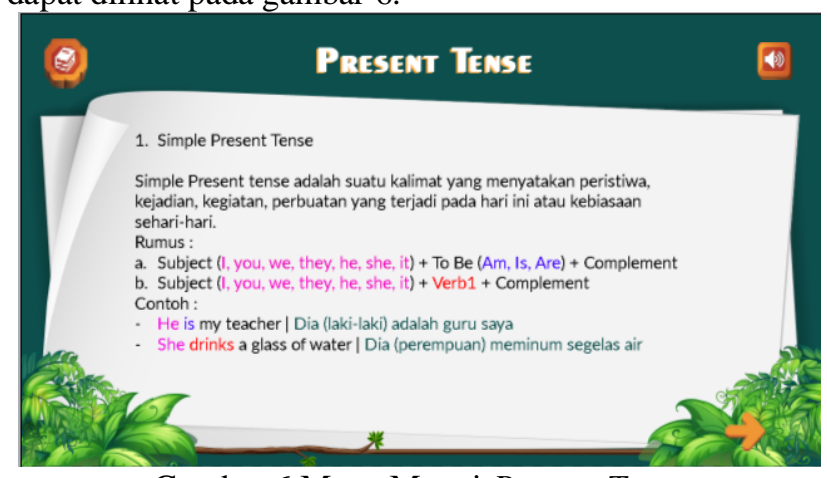

Gambar 6 Menu Materi Present Tense

\section{Menu Latihan}

Pada halaman ini terdapat icon tombol home untuk kembali ke menu utama, dan juga terdapat empat icon tombol pilihan yaitu a, b, c, dan d. tampilan menu materi dapat dilihat pada gambar 7.

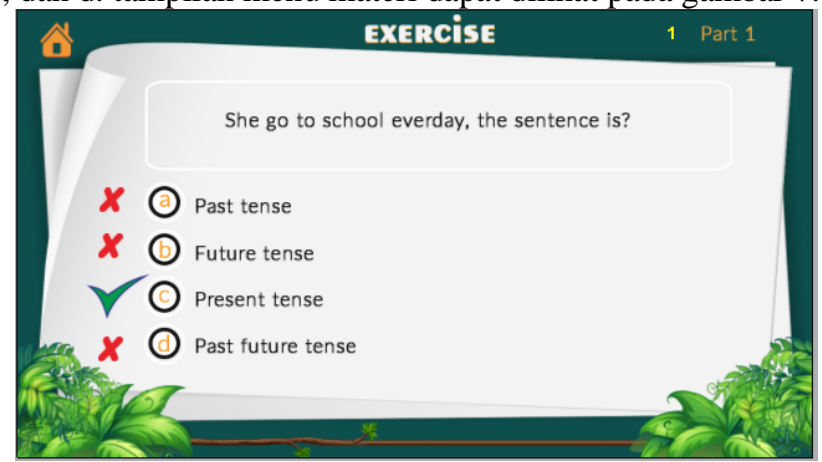

Gambar 7 Menu Latihan

\section{Menu Permainan}

Pada halaman ini terdapat icon tombol pilih level yaitu terdiri dari 1 sampai 32 level, icon refresh untuk merestart ulang level dari awal dan icon tombol home untuk kembali ke menu utama. Tampilan menu permainan dapat dilihat pada gambar 8 . 


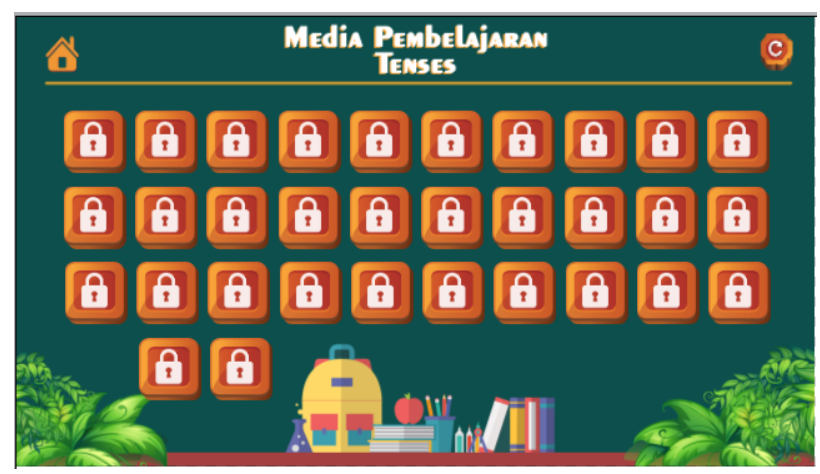

Gambar 8 Menu Latihan

\section{Menu Permainan Labirin}

Pada halaman ini terdapat sebuah papan permainan berbentuk labirin, dimana terdapat soal yang nantinya pemain akan mencari salah satu jawaban yang tepat dengan cara menggunakan karakter yang telah disediakan dan sesuai pilihan jawaban yang ada di setiap level. Pada halaman ini juga terdapat icon tombol home untuk kembali ke menu permainan, icon tombol keypad kanan, kiri, atas, dan bawah untuk menggerakan karakter, serta waktu untuk menyelesaikan tantangan. Tampilan permainan labirin dapat dilihat pada gambar 9.

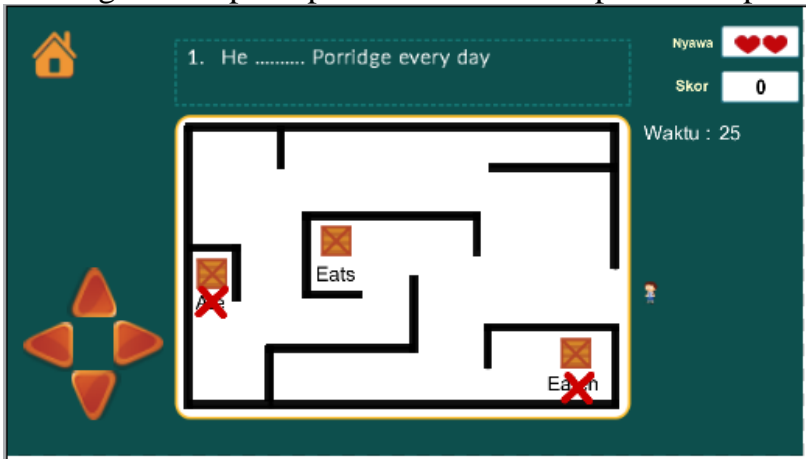

\section{Menu Tentang}

Gambar 9 Menu Permainan Labirin

Tampilan Halaman menu tentang menampilakan profil pembuat program dan tombol kembali. Tampilan menu tentang dapat dilihat pada gambar 10 .

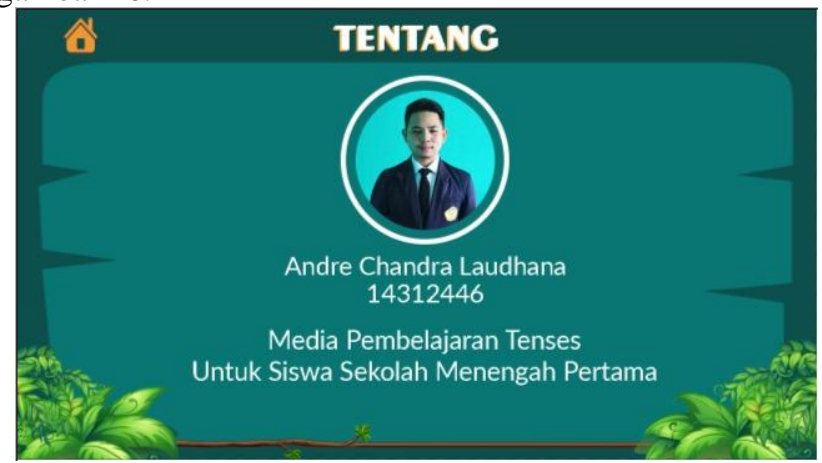

Gambar 10 Menu Tentang

\section{Menu Petunjuk}

Tampilan Halaman menu petunjuk menampilkan sebuah petunjuk seperti fungsi dari masing-masing tombol dan isi dari setiap menu pada menu utama. Tampilan menu petunjuk dapat dilihat pada gambar 11 . 


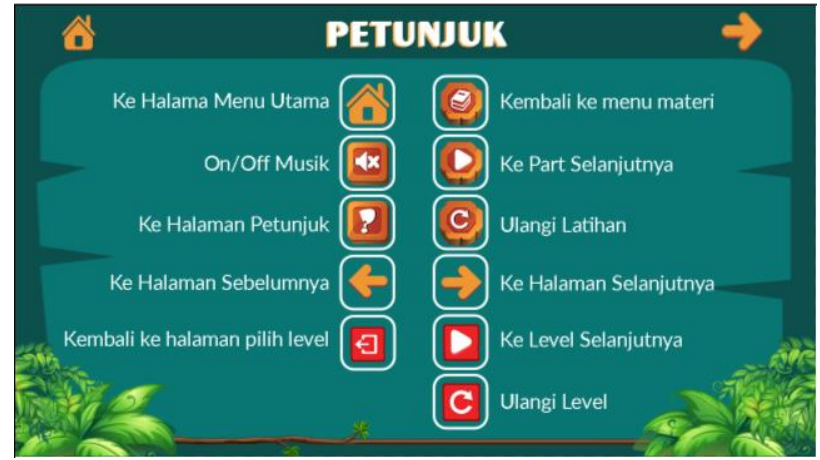

Gambar 11 Menu Petunjuk

\section{Menu Keluar}

Halaman menu keluar menampilkan pop-up ya atau tidak untuk keluar dari apikasi tenses. Tampilan menu materi dapat dilihat pada gambar 12 .

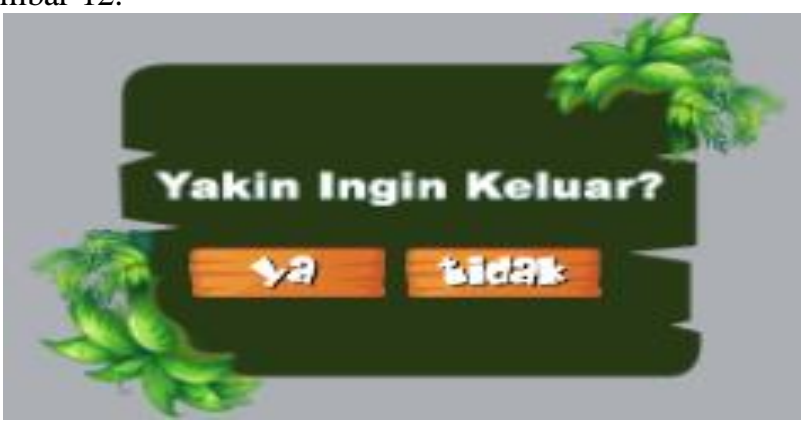

Gambar 12 Menu Keluar

\section{Pengujian}

Tahap pengujian Aplikasi Media Pembelajaran Tenses dilakukan dengan melalui pengujian Alpha (Blackbox) dan Beta.

\section{Pengujian Alpha}

Berdasarkan rencana pengujian, maka dapat dilakukan pengujian alpha dengan Blackbox pada aplikasi "Media Pembelajaran Tenses" yang di jelaskan pada tabel 1.

Tabel 2 Hasil Pengujian Aplikasi

\begin{tabular}{|c|l|c|c|}
\hline \multirow{2}{*}{ No } & \multicolumn{2}{|c|}{ Aktivitas Pengujian } & \multicolumn{2}{c|}{ Hasil pengujian } \\
\cline { 3 - 4 } & & Sukses & Gagal \\
\hline 1 & Klik Tombol Materi & $\sqrt{ }$ & \\
\hline 2 & Klik Tombol Materi present tense & $\sqrt{ }$ & \\
\hline 3 & Klik Tombol Materi past tense & $\sqrt{ }$ & \\
\hline 4 & Klik Tombol Materi future tense & $\sqrt{ }$ & \\
\hline 5 & Klik Tombol Materi past future tense & $\sqrt{ }$ & \\
\hline 6 & Klik Tombol Latihan & $\sqrt{ }$ & \\
\hline 7 & Klik Tombol Permainan & $\sqrt{ }$ & \\
\hline 8 & Klik Tombol Level 1 sampai 32 & $\sqrt{ }$ & \\
\hline 9 & Klik Tombol Tentang & $\sqrt{ }$ & \\
\hline 10 & Klik Tombol Petunjuk & $\sqrt{ }$ & \\
\hline 11 & Klik Tombol Keluar & $\sqrt{ }$ & \\
\hline 12 & Klik Tombol Mulai & $\sqrt{ }$ & \\
\hline 13 & Klik Tombol Home & $\sqrt{ }$ & \\
\hline 14 & Klik Tombol Suara & & \\
\hline 15 & Klik Tombol Next & \\
\hline
\end{tabular}




\begin{tabular}{|c|l|c|c|}
\hline 16 & Klik Tombol Back & $\sqrt{ }$ & \\
\hline 17 & Klik Tombol Book & $\sqrt{ }$ & \\
\hline 18 & Klik Tombol Keypad(Kanan,kiri,atas,bawah) & $\sqrt{ }$ & \\
\hline 19 & Klik Tombol Next Level & $\sqrt{ }$ & \\
\hline 20 & Klik Tombol Refresh & $\sqrt{ }$ & \\
\hline 21 & Klik Tombol Keluar permainan & $\sqrt{ }$ & \\
\hline
\end{tabular}

Berdasarkan hasil pengujian alpha yang telah dilakukan, menunjukan bahwa aplikasi yang dibangun sudah memenuhi persyaratan fungsional. Akan tetapi, pada prosesnya masih memungkinkan untuk terjadi kesalahan. Secara fungsional sistem yang telah dibangun sudah dapat menghasilkan keluaran yang diharapkan.

\section{Pengujian Beta}

Pengujian beta adalah pengujian yang dilakukan secara objektif, pengujian ini dilakukan secara langsung terhadap siswa/i SMP PGRI 6 yang ada di Bandar lampung. Proses yang dilakukan dengan menggunakan pembuatan kuisioner terhadapa user atau penggunan dari aplikasi yang dibuat selanjutnya dibagikan kepada pengguna dengan mengambil sebagian sempel pengguna 58 orang siswa/i dari kelas 1 dan 2 sekolah tersebut. Kuisioner ini terdiri dati 5 pertanyaan yang diberikan dengan menggunakan skala jawaban "Ya" dan "Tidak".

Berdasarkan hasil pengujian yang telah dilakukan dapat disimpulkan bahwa aplikasi "Media Pembelajaran Tenses" sudah sesuai dengan kebutuhan pengguna karena sebagian besar responden memilih jawaban "YA" dari 5 pertanyaan yang diberikan dari angket kuesioner. Adapun ketentuan skala untuk setiap pertanyaan pada tabel 3.

Tabel 3 Hasil Pengujian Beta

\begin{tabular}{|c|c|c|c|c|c|c|}
\hline \multirow[t]{2}{*}{ No } & \multirow[t]{2}{*}{ Pertanyaan } & \multicolumn{2}{|c|}{ Kategori jawaban } & \multirow{2}{*}{$\begin{array}{l}\text { Jumlah } \\
\text { populasi } \\
\text { sampel }\end{array}$} & \multicolumn{2}{|c|}{$\begin{array}{c}\text { Jumlah } \\
\text { Persentase (\%) }\end{array}$} \\
\hline & & $\mathrm{Ya}$ & Tidak & & $\mathrm{Ya}$ & Tidak \\
\hline 1 & Apakah aplikasi mudah digunakan? & 57 & 1 & 58 & $98 \%$ & $2 \%$ \\
\hline 2 & $\begin{array}{l}\text { Apakah anda dapat belajar tenses menggunakan } \\
\text { aplikasi "Media Pembelajaran Tenses"? }\end{array}$ & 58 & - & 58 & $100 \%$ & - \\
\hline 3 & $\begin{array}{l}\text { Apakah aplikasi "Media Pembelajaran Tenses" } \\
\text { membuat anda memudahkan belajar tenses? }\end{array}$ & 58 & - & 58 & $100 \%$ & - \\
\hline 4 & $\begin{array}{l}\text { Setelah menggunakan aplikasi "Media } \\
\text { Pembelajaran Tenses" apakah anda memahami } \\
\text { beberapa materi? }\end{array}$ & 53 & 5 & 58 & $91 \%$ & $9 \%$ \\
\hline 5 & $\begin{array}{l}\text { Apakah anda suka dengan aplikasi "Media } \\
\text { Pembalajaran Tenses"? }\end{array}$ & 58 & - & 58 & $100 \%$ & - \\
\hline
\end{tabular}

\section{SIMPULAN}

Kesimpulan dari penelitian mengenai media pembelajaran tenses berbasis android adalah sebagai berikut

1. Aplikasi media pembelajaran tenses yang dapat membantu dan mempermudah siswa/i untuk mengenal pelajaran tenses sambil bermain dan memudahkan siswa/i memahami materi-materi yang belum di sampaikan di kelas.

2. Berdsarkan hasil pengujian aplikasi media pembelajaran tenses dari pengujian alpha dengan menggunakan blackbox menunjukan bahwa aplikasi yang dibangun sudah memenuhi persyaratan fungsional. Secara fungsional sistem yang telah dibangun sudah dapat menghasilkan keluaran yang diharapkan. Dari hasil pengujian beta yang telah dilakukan dapat disimpulkan bahwa aplikasi media pembelajaran tenses sudah sesuai dengan kebutuhan pengguna karena $100 \%$ responden menjawab "YA" bahwa aplikasi mudah digunakan, 98\% responden menjawab "YA" bahwa siswa dapat belajar tenses, 100\% responden menjawab "YA" bahwa aplikasi membuat mempermudah belajar tenses, 91\% responden menjawab "YA" bahwa siswa dapat memahami materi mengenai tenses, dan 100\% responden menjawab "YA" bahwa siswa suka dengan aplikasi tenses. 
Setelah melakukan evaluasi pada penelitian yang telah dilakukan dan juga beberapa masukan dari guru SMP PGRI 6 Bandar Lampung, diharapkan agar aplikasi ini dapat dikembangkan lebih lanjut sehingga menjadi lebih sempurna lagi, saran untuk pengembang selanjutnya adalah sebagai berikut:

1. Pengembangan aplikasi dapat menambahkan keterampilan - keterampilan berbahasa yang lain, misalnya family tree, numbers, things around, dan lainnya yang berhubungan dengan materi pembelajaran di sekolah.

2. Pengembangan aplikasi dapat menambahkan level permainan dan menambahkan jenis game yang lain.

\section{UCAPAN TERIMA KASIH}

Terimakasih kami ucapkan kepada seluruh responden yang membantu terlaksannya penelitian ini dan Universitas Teknokrat Indonesia yang mendukung dalam penyelesaian penelitian ini.

\section{DAFTAR PUSTAKA}

Adrian, Q. J. 2019. Game Edukasi Pembelajaran Matematika Untuk Anak SD Kelas 1 Dan 2 Berbasis Android. Jurnal Teknoinfo.

Arsyad, A. 2011 “Aplikasi Media Pembelajaran Untuk Anka Usia Dini Berbasis Android”, Jurnal Teknologi Pelita Bangsa, Vol 6, pp. 112-113.

Arum, R., Herlinawati, S. P., Pratama, A. 2015. Rancang Bangun Sistem Pembelajaran Tenses Berbasis Macromedia Flash 8, Jurnal Teknik Informatika dan Teknik Elektro Terapan, Vol. 1, No. 1 pp. 1-6.

Binanto, I. 2015. Game Pembelajaran Matematika Untuk Anak SD Kelas 1 dan 2 Berbasis Android Menggunakan Construct 2. E-Proceeding of Applied Science, Vol 1, p. 2090.

Gullen, A. 2016. "Pembuatan Game Labirin Menggunakan Aplikasi Construct 2 Berbasis Online", Elektronik Sistem Informasi dan Komputer, Vol 2, p.9.

Kholiani, W., I. Rosyadi, I. 2016 "Media Pembelajaran Tenses Bahasa Inggris Pada English Club Berbasis Adobe Flash CS3", Surya Informatika, Vol 2, No. 1 pp. 34-39.

Rahmanto, Y., Utama, R. Y. 2018. Penerapan Teknologi Web3D Berbasis Android sebagai Media Pembelajaran Gerakan Dasar Silat - Jurnal TAM (Technology Acceptance Model).

Rosa. A.S, Shalahuddin, M. 2016 Rekayasa Perangkat Lunak Terstruktur dan Berorientasi Objek. Bandung, Informatika Bandung.

Saputra, V., H. Darwis, D., Febrianto, E. 2020. Rancang Bangun Aplikasi Game Matematika Untuk Penyandang Tunagrahita Berbasis Mobile - Jurnal Komputer dan Informatika.

Safaat, H. N. 2011. Pengukuran Kinerja Goodreads Application Programming Interface (API) Pada Aplikasi Mobile Android., Jurnal Informatika, Vol 2, pp.1-9.

Shobirin, R. 2008. Rancang Bangun Aplikasi Pembelajaran Untuk Anak Umur 6-9 Tahun Berbasis Android, EJournal Teknik Informatika, Vol 7.

Susanto, S. A., Mahfan. 2005 Complete English Grammar, Jakarta : Sandro Jaya Jakarta, 2005.

Vaughan, T. 2016. Rancang Bangun Aplikasi Pembelajaran Untuk Anak Umur 6-9 Tahun Berbasis Android. Ejournal Teknik Informatika, Vol 7. 